\title{
AMBIVALENCE IN ETHNOCENTRIC BIAS
}

\author{
Ting-Hsiang Tseng, Feng Chia University, Taiwan \\ George Balabanis, City University London, UK \\ Matthew Liu, University of Macau, China
}

\begin{abstract}
Research indicates that consumers unequivocally tend to be biased in favor of their home country's products and against foreign products (Herche 1992; Levin and Jasper 1996; Shimp and Sharma 1987; Supphellen and Gronhaug 2003; Supphellen and Rittenburg 2001; Verlegh 2007). This bi-directional phenomenon of biased perceptions of products according to their domesticity is called "ethnocentric bias" (toward domestic and foreign products). Nevertheless, ethnocentric bias could be contradict between explicit and implicit attitudes (Maison et al. 2004), and varied across product categories as well (Balabanis and Diamantopoulos 2004; Cleveland et al. 2009). Although extant research has empirically established the existence of those variations, systematically theoretical explanations are still in their infancy.

This paper focuses on the variations of ethnocentric bias between explicit and implicit attitudes across product categories. Based on previous research, the study attempts to identify the kinds of product categories to which consumers will show similar patterns in explicit and implicit ethnocentric biases, and the kinds of product categories to which consumers will not. Empirical studies have found that when consumers hold ambivalent attitudes toward a country, their willingness to buy emblematic brands of that country will become weaker (Russell et al. 2011). Thus, to identify product categories toward which ethnocentric consumers may hold ambivalent attitudes (e.g., inconsistent explicit and implicit attitudes) is critical for international marketers.
\end{abstract}

The results exhibit several interesting findings: for typical products, consumer ethnocentrism is positively related to consumers' explicit attitudes toward domestic products, and negatively related to consumers' explicit attitudes toward foreign products. However, such ethnocentric bias cannot be found for consumers' implicit attitudes. In other words, ethnocentric bias is obvious explicitly but not implicitly for typical products. Ethnocentric consumers will show their preference for domestic typical products and their prejudice for foreign typical products, but at the same time hold implicit attitudes similar to less ethnocentric consumers.

For atypical products, consumer ethnocentrism is positively related to consumers' attitudes toward domestic products both explicitly and implicitly. There is no ambivalence in this case. Atypical products are usually products of those weak industries of a country. Ethnocentric consumers have strong sympathy toward those domestic products and would like to sincerely support those industries. On the other hand, there is ambivalence in ethnocentric bias again for foreign atypical products. Although ethnocentric consumers tend to consistently show explicit prejudice to foreign products, associations with atypical foreign products are so weak in consumers' minds that no significant relationship between consumer ethnocentrism and consumers' implicit attitudes could be found.

In summary, consumers tend to show ambivalent ethnocentric bias toward typical products. While their explicit ethnocentric biases are quite obvious, their implicit ethnocentric biases are not. This result implies that typical foreign products may suffer less from consumer ethnocentrism.

References Available Upon Request 